\title{
Development of a metallophyte spatial database covering Australia
}

\author{
A. Pudmenzky Centre for Mined Land Rehabilitation, The University of Queensland, Australia \\ L. Rossato Centre for Mined Land Rehabilitation, The University of Queensland, Australia \\ D. Doley Centre for Mined Land Rehabilitation, The University of Queensland, Australia \\ C. Ramirez Centre for Mined Land Rehabilitation, The University of Queensland, Australia
}

A.J.M. Baker School of Botany, The University of Melbourne; and Environmental Earth Sciences International Pty Ltd, Australia

\begin{abstract}
Australia is characterised by a high endemic plant diversity and the presence of large areas of serpentine soils naturally rich in heavy metals, which are characteristically occupied by metal-tolerant plants, i.e. metallophytes. Metallophytes are ideal for decontamination and restoration of metal-contaminated sites. Unfortunately, many metallophyte species are under threat of extinction from mining activities in the underlying metal-rich substrates, and urgent action is required to conserve them before they are eliminated.

A centralised metallophyte database covering Australia has been initiated to manage information on metaltolerant native plant species, habitat and substrate characteristics. The database has also been linked to Phoenix, a 3D-GIS program which allows the user to view the results of spatial database queries superimposed onto an aerial photograph of Australia, and to extract information such as metal concentrations in substrata and plant parts. Since access to the database follows the Convention on International Trade in Endangered Species of Wild Fauna and Flora (CITES) guidelines in not allowing the exact location of rare or endangered species to be revealed, users who require this information will first need to acquire the relevant Australian regulatory authorisations.

Interrogation of the metallophyte database constructed so far established that work in this field in Australia has largely prioritised the identification of native metal accumulators and hyperaccumulators (14 in Australia), and that far less attention has been paid to the identification of other metal-tolerant, but nonaccumulating plants, i.e. excluders. However, it is these latter species that will be critical to the success and safety of rehabilitating metal tailings facilities. Australia is highly biodiverse, with 25,000 native species. It is therefore very likely that many more metallophytes from the Australian flora remain to be discovered. Improving and expanding this centralised database is crucial and constitutes one of the research priorities for the conservation of the unique Australian metallophyte biodiversity and mine rehabilitation. The database will assist mining companies in planning operations so as to avoid disturbance of vulnerable and valuable metallophyte biodiversity, as well as support decision-making for remediation and restoration exercises.
\end{abstract}

\section{Introduction}

Australia is characterised by an extremely high endemic plant diversity (Williams et al., 1994; Myers et al., 2000) and relatively large areas of serpentine soils with elevated levels of heavy metals, which are characteristically occupied by metal-tolerant plants known as metallophytes (Augee and Fox, 2000). Plant tolerance to metals and associated factors is a prerequisite for growth on contaminated lands and mine tailings (Bradshaw and Chadwick, 1980), and plant strategies may involve either metal accumulation into above-ground parts, or metal exclusion (Baker, 1981). Metallophytes are thus a unique biological resource for remediation of contaminated lands and restoration of mine sites and tailings (Whiting et al., 2004). Unfortunately, metallophytes are threatened by the activities of the minerals industry and immediate action to conserve them is imperative before land-clearing activities eliminate them (Baker and Whiting, 2008). Whiting et al. (2004) identified the development of a well managed and widely accessible metallophyte database as one of the three immediate research priorities for the conservation of the metallophyte 
biodiversity. To date, there have been a few attempts to create such a public database, including METALS (metal-accumulating plants) and Environment Canada's PHYTOREM databases - but their global coverage is patchy and focusses on plant use for remediation purposes, as opposed to in situ conservation of metallophyte habitat and populations (Baker and Whiting, 2008). In contrast, there are voluminous research data and compilations of species and habitat held by tertiary institutions and herbaria world-wide, but these are specialised and rarely accessible to the public in a readily usable form.

The objectives of this project are to: i) design a metallophyte relational database prototype; ii) populate the database with existing scientific and herbaria information on metal tolerance of Australian native plant species; and iii) link it to a 3D-GIS program to be able to perform spatial and textual queries of the database.

\section{Methodology}

\subsection{Development of a spatial metallophyte database covering Australia}

The construction of the metallophyte database containing existing information on metal tolerance (as tested experimentally) and habitat and distribution of Australian native plant species was divided into five steps: data sourcing; database design and normalisation; database interface development; database population; and database linking with Phoenix GIS (Pudmenzky et al., 2006).

\subsubsection{Data sourcing}

Existing information on experimentally tested metal tolerance of native Australian species, their occurrences, substrate/soil characteristics, habitat descriptions, metal extraction methods, and concentrations of metals in substrata and plant parts was extracted from the literature, herbarium records and materials. Additional data was accessed from the METALS FoxPro (outdated) database produced by Environmental Consultancy (ECUS Ltd) at the University of Sheffield, United Kingdom, originally for Noranda/Falconbridge, and the Environment Canada's PHYTOREM database (Baker and Whiting, 2008).

\subsubsection{Database design and normalisation}

A relational database (Garmany et al., 2005) was developed using Microsoft Access 2007. The main difference between a relational database and other database types, such as hierarchical or network databases (data collections in spreadsheet tables, text files or similar are not considered to be databases), is the use of a unique identifier or 'key' enabling the developer to separate the data into several different tables and then relate desired fields during a query using join operations. Based on the information extracted from the data sources mentioned above, the database entities, their types and their relationship with each other were determined and 49 database fields distributed over 17 tables were created. A normalisation process (Codd, 1970) ensured no redundant information was contained in the tables, and also minimised the number of insert, delete and update transactions (Elmasri and Navathe, 2006).

\subsubsection{Database interface development}

A forms-based data entry user interface was developed using the Microsoft Access forms facility. A visual basic program module had to be developed to allow the display of plant images in this interface.

\subsubsection{Database population}

The database was populated using the forms interface by manually entering information from the data sources.

\subsubsection{Database linking with Phoenix GIS}

In order to link the database to the Phoenix GIS system a database view was created containing a unique Phoenix 'record key' field consisting of the location field's longitude, latitude and the species botanical name for each recorded plant specimen extracted from the data sources. Each species was also represented in its spatial location on the Australian GIS model surface map as a coloured marker and linked to its corresponding database record(s) in the database view. Using the ability of the Phoenix GIS to attach images and electronic documents to markers, images of the plant species investigated were included and the 
scientific publications related to the metallophyte study were attached to each species sampler as a .pdf file whenever they were available.

\section{$3 \quad$ Results and future directions}

A spatial metallophyte database covering Australia was initiated to centralise, manage and facilitate access to existing and new information on native plant species tolerant to metals and metalloids that could be used for both habitat and species conservation purposes, as well as remediation of metal-contaminated sites and mine tailings. Heavy metals and metalloids captured in the database include: silver (Ag), arsenic (As), gold (Au), cadmium $(\mathrm{Cd})$, cobalt $(\mathrm{Co})$, chromium $(\mathrm{Cr})$, copper $(\mathrm{Cu})$, iron $(\mathrm{Fe})$, manganese $(\mathrm{Mn})$, molybdenum $(\mathrm{Mo})$, nickel $(\mathrm{Ni})$, lead $(\mathrm{Pb})$, antimony $(\mathrm{Sb})$, selenium $(\mathrm{Se})$, and zinc $(\mathrm{Zn})$. Information on soil/substrate characteristics $(\mathrm{pH}$, electrical conductivity, total and bioavailable metal content), habitat descriptions and images of metallophytes, and electronic versions of published papers are also included in the database. The metallophyte database has also been linked to Phoenix (Figure 1), which allows the user to visualise the results of database queries on an aerial photograph draped over the true topography of Australia and to extract information such as metal concentration values or metal extraction methods used (Figure 2).

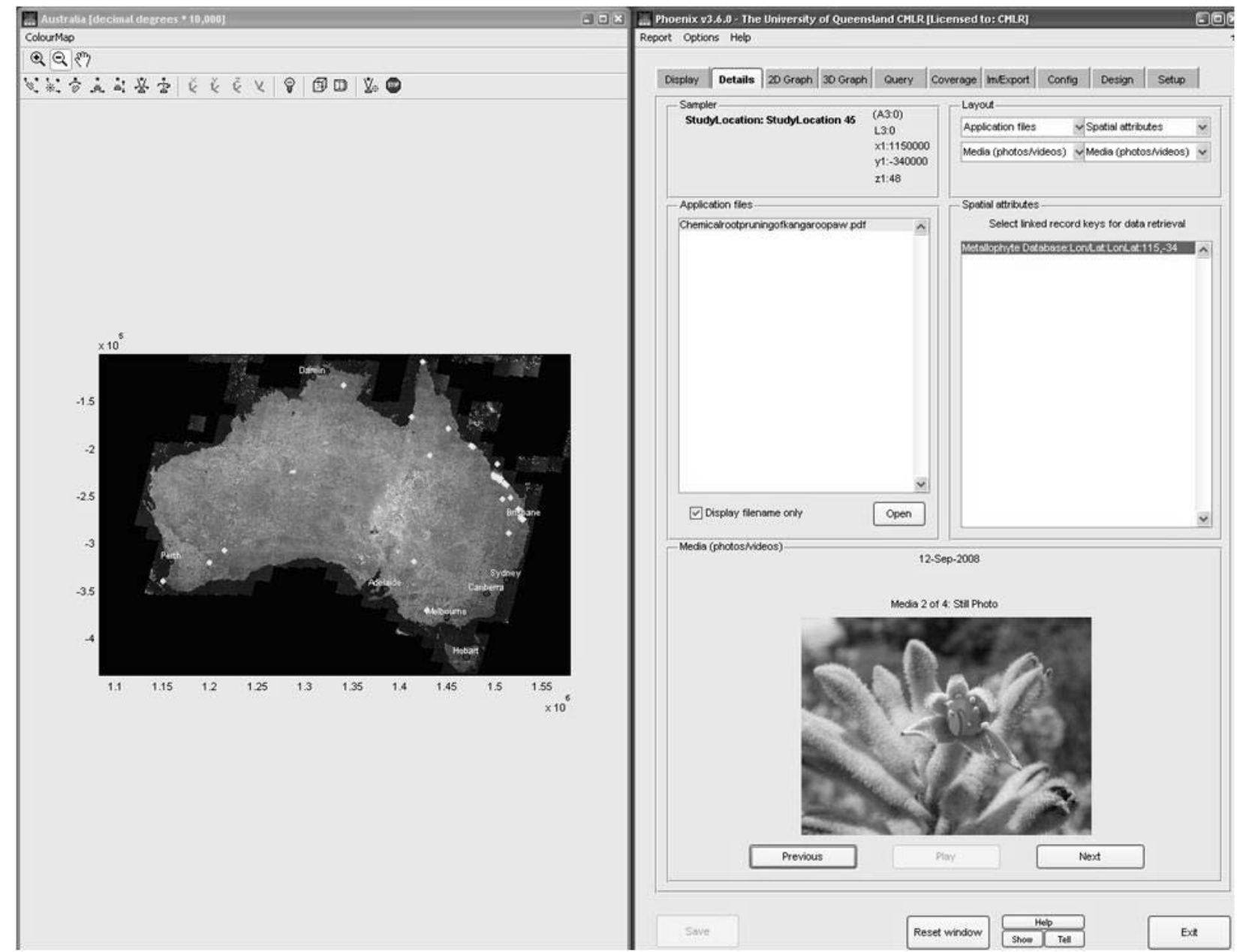

Figure 1 Phoenix screen shot showing an aerial photo of Australia in the map window on the left and information attached to a metallophyte sampler on the control panel window on the right. The selected metallophyte sampler has a .pdf document, a relational database attribute and four photos attached to it

Interrogating the Australian metallophyte database confirmed the statement of Baker and Whiting (2008) that the available scientific literature has mainly focussed on the identification of native metal accumulators and hyperaccumulators, and that there has been limited surveys focussing on the identification of other metal- 
tolerant but non-accumulating plants, i.e. excluders. Querying the database for native metal-accumulating species returned only 14 plant species characterised as hyperaccumulators, including:

- Ni hyperaccumulators Rostellularia adscendens var hispida (Domin.) R.M. Barker (Snake Creek, QLD); Commelina ensifolia R.Br. (Gunnawarra, QLD); Stackhousia tryonii F.M. Bailey (Rockhampton \& South Percy Island, QLD); Pimelea leptospermoides F. Muell. (Rockhampton, QLD) and Hybanthus floribundus (Lindl.) F. Muell. (Eastern Goldfields, WA).

- Se hyperaccumulators such as Neptunia amplexicaulis Domin and Morinda reticulata Benth.

- Mn hyperaccumulators such as Gossia bidwillii (Benth.) N. Snow and Guymer (EA), Gossia bamagensis N. Snow and Guymer (EA); G. fragrantissima (F.Muell. ex Benth.) N. Snow and Guymer (EA); G. sankowksiorum (F. Muell. ex Benth.) N. Snow \& Guymer (EA); G. gonoclada (F. Muell. ex Benth.) N. Snow and Guymer (EA); and Maytenus cunninghamii (Hook.) Loes. (EA).

- The Pb hyperaccumulator Polycarpaea synandra F. Muell. (NT).

Australia is the second most plant biodiverse country in the world after Brazil, with 25,000 native species out of a total of 250,000 plant species globally. It is therefore very likely that many more metallophytes from the Australian flora remain to be discovered. The number of metallophytes identified is expected to increase in the next few decades as a result of the drive for remediation and restoration of contaminated sites and mining waste using tolerant native and local species (Baker and Whiting, 2008).

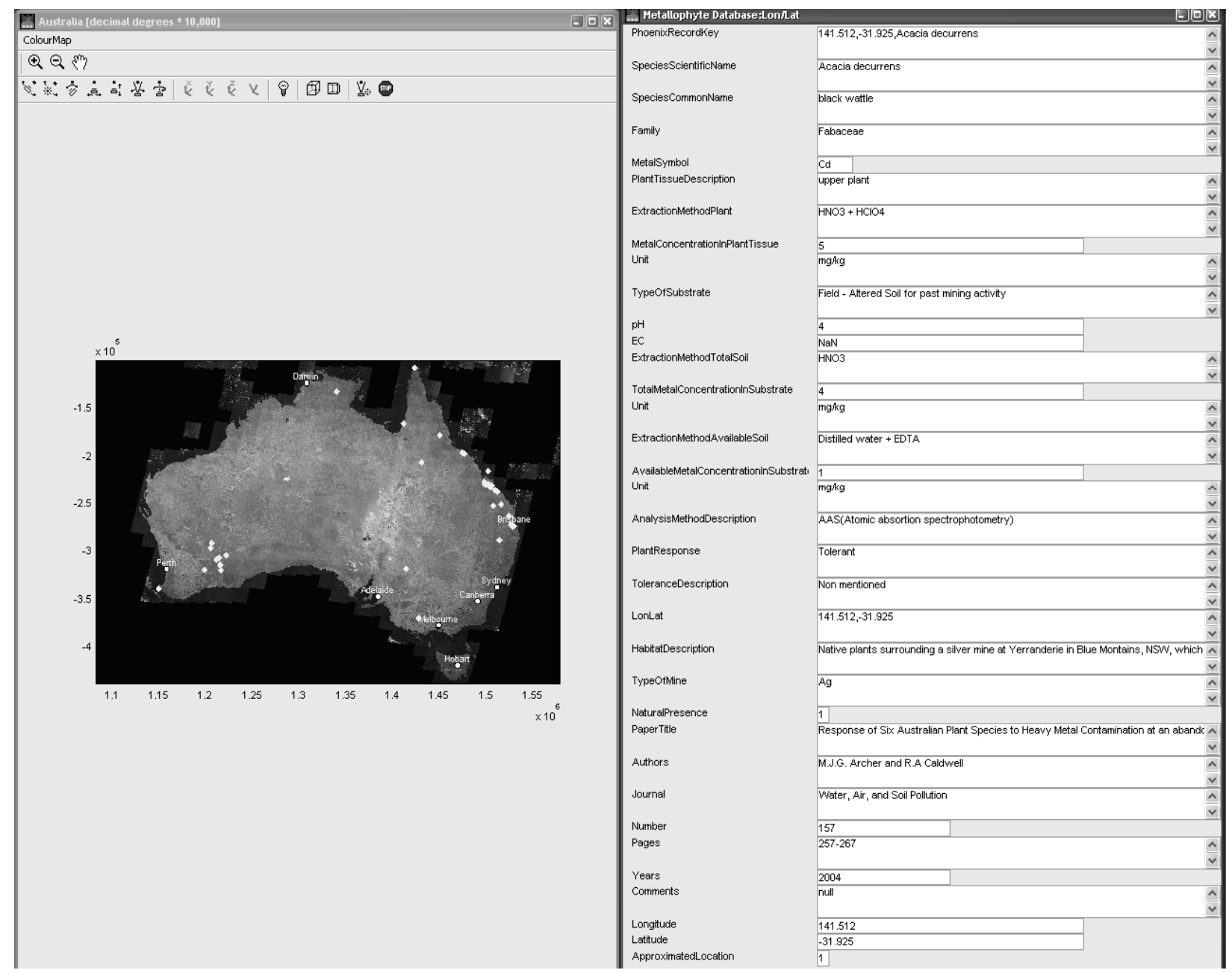

Figure 2 Phoenix interface showing the database information for a metallophyte sampler retrieved via a query. In the 'natural presence' and 'approximate location' fields, ' 1 ' is equal to yes, 'NaN' and 'null' (in ' $\mathrm{EC}$ ' and 'comments') indicate 'no value' found for those fields 
Future work on the metallophyte database includes performing quality control checking of its content, and maintaining and expanding its coverage and content using new information from the literature and analysis of plant specimens from ongoing geobotanical surveys of serpentine landscapes, herbariums and metalliferous mine sites in Australia. The prototype Microsoft Access 2007 database can also be upsized to a corporate distributed SQL server database but it will be important to ensure that the database follows the Convention on International Trade in Endangered Species of Wild Fauna and Flora (CITES) guidelines, i.e. encodes the location of rare and endangered species, to prohibit uncontrolled bio-prospecting of what may be highly localised, endemic and vulnerable plant populations.

\section{Acknowledgements}

This study was supported by the Centre for Mined Land Rehabilitation at The University of Queensland, Australia. The comments of the anonymous reviewers are gratefully acknowledged.

\section{References}

Augee, M. and Fox, M. (2000) Biology of Australia and New Zealand, Benjamin Cummings, Australia.

Baker, A.J.M. (1981) Accumulators and excluders - strategies in the response of plants to heavy metals. Journal of Plant Nutrition Vol. 3, pp. 643-654.

Baker, A.J.M. and Whiting, S.N. (2008) Metallophytes - A unique biodiversity and biotechnological resource in the care of the minerals industry, In Proceedings of the Third International Seminar on Mine Closure, Mine Closure 2008, A.B. Fourie, M. Tibbett, I.M. Weiersbye, P. Dye (eds), 14-17 October 2008, Johannesburg, South Africa, Australian Centre for Geomechanics, Perth, pp. 13-20.

Bradshaw, A.D. and Chadwick, M.J. (1980) The restoration of land. Blackwell Scientific Publications, Oxford.

Codd, E.F. (1970) A relational model of data for large shared data banks. Communications of the ACM, Vol. 13(6), pp. $377-387$.

Elmasri, R. and Navathe, S.B. (2006) Fundamentals of database systems, Fifth Edition, Pearson, USA.

Garmany, J., Walker, J. and Clark, T. (2005) Logical database design principles, Auerbach Publication, USA, 180 p.

Myers, N., Mittermeier, R.A., Mittermeier, C.G., da Fonseca, G.A.B. and Kent, J. (2000) Biodiversity hotspots for conservation priorities, Nature, Vol. 403, pp. 853-858.

Pudmenzky, A., Rossato, L., Mcllveen, G. and Mulligan, D. (2006) Phoenix: A Mine Environment Data Visualisation and Management System, In Proceedings of the First International Seminar on Mine Closure, Mine Closure 2006, A.B. Fourie, M. Tibbett (eds), 13-15 September 2006, Australian Centre for Geomechanics, Perth, Australia, pp. 773-779.

Whiting, S.N., Reeves, R.D., Richards, D., Johnson, M.S., Cooke, J.A., Malaisse, F., Paton, A., Smith, J.A.C., Angle, J.S., Chaney, R.L., Ginocchio, R., Jaffré, T., Johns, R., McIntyre, T., Purvis, O.W., Salt, D.E., Schat, H., Zhao, F.J. and Baker, A.J.M. (2004) Research priorities for conservation of metallophytes and their potential for restoration and site remediation, Restoration Ecology, Vol. 12, pp. 106-116.

Williams, P.H., Humphries, C.J. and Gaston, K.J. (1994) Centre of seed-plant diversity: the family way, Proceedings of the Royal Society of London, Biological Sciences, Vol. 256, pp. 67-70. 